\title{
Effects of sound localization stimuli on eye-movement reaction time
}

\author{
PAUL DOWNEY and LEONARD BROSGOLE \\ St. John's University, Jamaica, New York 11439
}

\begin{abstract}
Eye-movement reaction times to sound location stimuli were obtained from human subjects told to look rapidly toward a sound and compared with those obtained from subjects instructed to look in the opposite direction toward a silent loudspeaker. In an independent-groups design, all combinations of 50-, 500-, and 5,000- $\mathrm{Hz}$ tones and rise times of .5 and $25.0 \mathrm{msec}$ were used. An analysis of variance showed that the reaction time of eye movements toward the sound were faster than those which oriented the eyes away from the sound. Subsequent planned comparisons and simple effects showed that the speed of the ocular orientation toward the sound decreased only under one set of conditions, namely, at $5,000 \mathrm{~Hz}, 25.0 \mathrm{msec}$ rise time, where the localizability of the signal was reduced.
\end{abstract}

Considerable evidence exists that the medial superior olivary nucleus (MSO) participates in binaural sound localization. This is based partly on anatomical evidence that single MSO cells receive synaptic input from both the left and right cochlear nuclei (Harrison \& Feldman, 1970; Stottler, 1953; Strominger \& Strominger, 1971).

Electrophysiological studies of the MSO using dichotic clicks indicate that the response of single MSO cells depends on small differences in the arrival time of sounds at the two ears (Galambos, Schwartzkopff, \& Rupert, 1959; Hall, 1965; Masterton, Jane, \& Diamond, 1967). In addition, sound localization based on time differences is disrupted by lesions in afferent and efferent connections to the MSO (Masterton et al., 1967).

There is also some indication that the importance of interaural time differences for lateralization and localization of sound in man is greatest below $1,500 \mathrm{~Hz}$ (Feddersen, Teas, Sandel, \& Jeffress, 1957; Mills, 1960; Sandel, Feddersen, Teas, \& Jeffress, 1955). The MSO in man may operate within this range. In cats (Guinan, Norris, \& Guinan, 1972) and dogs (Goldberg \& Brown, 1968), most MSO cells respond to frequencies below $10 \mathrm{kHz}$. Moreover, Masterton, Thompson, Bechtold, and Robards (1975) have shown that in the cat, rat, hedgehog, and tree shrew, the ability to localize middle- and lowfrequency tones corresponds to the size of the MSO in each species. This supports the view that the MSO is a time analyzer for middle- to low-frequency sound localization. It has been suggested that localization of high frequencies depends on interaural intensity differences (Fedderson et al., 1957; Mills, 1960) and is

This experiment was conducted in the Psychology Department of St. John's University. The authors wish to thank Lewis Aron, Robert Columbo, Alan Jacobsen, and Paul Ulatowski for invaluable assistance in conducting this research. Requests for reprints should be sent to Paul Downey, Psychology Department, St. John's University, Jamaica, New York 11439. mediated by a system or systems other than the MSO (Erulkar, 1972; Masterton et al., 1975).

Some anatomical evidence suggests that the MSO is involved in the control of reflexive orientation of eyes toward the location of sound stimuli. Irving and Harrison (1967) found that variations in the size of the MSO in different mammalian species are positively correlated with the diameter of the eye and the size of the sixth (VI) cranial nerve nucleus, which innervates ocular muscles controlling lateral eye movements. Moreover, the slope of the correlation obtained in animals with predominantly rod retinae was different from that of animals with cone retinae. In addition, Rasmussen (1964) has described descending fibers from the MSO that enter the cervical cord, which may affect neck muscles controlling reflex movements of the head toward a sound source.

The view that emerges from the above research is that the localization of middle- and low-frequency tones depends on the response of the MSO to interaural time differences. In addition, the MSO may be part of a visual-auditory system controlling reflex orientation of head and eyes toward a sound. These characteristics should be prominent in species (such as man) that have a large MSO and a well developed visual system.

The purpose of the following experiment was to test for characteristics of MSO functioning in man. This was done by comparing the reaction time of eye movements toward or away from a loudspeaker. It was expected that subjects instructed to look toward the source of a sound stimulus would have faster reaction times than subjects told to look in the opposite direction (toward a silent loudspeaker). It was also expected that these differences in reaction time would vary with the frequency and rise time of stimuli. In the present experiment, tones with three frequencies $(50,500$, and $5,000 \mathrm{~Hz})$ and two rise times $(.5$ and $25.0 \mathrm{msec})$ were used as auditory reaction time stimuli. 


\section{METHOD}

\section{General}

Brief $(300-\mathrm{msec})$ tone bursts, presented from one of two loudspeakers, served as a reaction time signal for subjects to initiate lateral movement of the eyes. The subjects were required to fixate a target located midway between the two loudspeakers. One loudspeaker was to the left of the mid-sagittal plane and the other was to the right. The signal was presented through the left loudspeaker on half the trials and through the right loudspeaker on the remaining half. While some subjects were required to move their eyes as quickly as possible toward the sounding loudspeaker, others were instructed to look rapidly toward the silent loudspeaker, and the reaction time from the onset of the signal to the movement of the eye in the opposite direction was recorded. This enabled us to compare the reaction time of eye movements toward a sound source with reaction time in the opposite direction.

In addition, this study was aimed at determining whether such differences in reaction time would vary as a function of changes in tonal frequency, or rise time of the signal. Three different frequencies $(50,500$, and $5,000 \mathrm{~Hz})$ and two rise times $(.5$ and $25.0 \mathrm{msec})$ were used. This was an independent-groups design, with 10 subjects assigned to each cell. Accordingly, the data were subjected to a 3 by 2 by 2 completely randomized block factorial design.

\section{Subjects}

Sixty males and 60 females participated in this study. Ranging in age from 18 to 66 years, their mean age was 24.8 years. All were naive as to the purpose of the experiment.

\section{Apparatus}

Testing took place in an L-shaped room with one leg of the $\mathrm{L}$ measuring $10.1 \times 2.1 \mathrm{~m}$ and the other leg measuring $3.1 \times 1.2 \mathrm{~m}$. The height of the room was $2.4 \mathrm{~m}$. The walls, floor, and ceiling of the room were constructed of sound-reflecting surfaces (concrete, plywood, and steel). Sound-generating and eyemovement recording equipment was located in a room adjacent to the testing area. Tones were generated by a Spectral Dynamics sweep oscillator (Model SD104-5). The oscillator was kept at full gain and was fed into a series of three Hunter interval timers (Model 111C). The timers controlled the duration of the tone, which was fixed at $300 \mathrm{msec}$. The onset of the tone was initiated by the depression of a manual trigger switch that activated the timers. The timers were in series between the oscillator and a Grason-Stadler electronic switch (Model 8-29-E) used to regulate rise time of the signal. The output of the switch was fed through a loudspeaker selector switch into one of the two loudspeakers located in the adjoining testing room. Two Utah 6-in. loudspeakers were used. They were rated at $8 \mathrm{ohms}$ and $2 \mathrm{~W}$, with a frequency response from 20 to $20,000 \mathrm{~Hz}$.

The reaction of the eyes to the auditory signal was monitored on a Beckman Type $\mathrm{R}$ dynograph. Beckman miniature skin electrodes were placed on the outer canthi of the eyes. The biopotential signal was fed through a Type 700 electrode selector panel into a Type 9859 direct nystagmus coupler. From there the signal was amplified by a Type $9481 \mathrm{~B}$ preamplifier and a Type $\mathbf{4 8 2}$ driver amplifier. Lateral eye movements were recorded on one channel of the dynograph, with a second channel used to record the onset and duration of the tone. The recording of the tone was accomplished by feeding the output of the Hunter timers directly into the second channel of the dynograph. The paper was driven at a speed of $250 \mathrm{~mm} / \mathrm{sec}$. This rapid paper speed permitted the accurate measurement of the latency between the onset of the tone and the departure of the eyes from baseline in the appropriate direction. It may be noted that a 10 -sec time constant was used in recording the eye movements, so as to preclude the appearance of dc drift in the record.

\section{Procedure}

The two loudspeakers were located on a wall adjoining the control room. They were $1.8 \mathrm{~m}$ apart horizontally. There was a $2.54-\mathrm{cm}$ square fixation target located between the loudspeakers. The subject was positioned in a Bausch and Lomb head and chin rest which was mounted on a Bausch and Lomb instrument table. The head and chin rest was $1.2 \mathrm{~m}$ from the fixation target which, in turn, was perpendicular to the nasion of the subject. The loudspeakers were separated by $73.8 \mathrm{deg}$ of visual arc from center to center. The center of each speaker was coincident with the eye level position. The eye-movement record was calibrated so that a shift in eye position from the fixation point to either of the speakers resulted in a full $2-\mathrm{cm}$ deflection of the pen.

There were a total of 24 trials, with the tone coming from the left on half the trials and from the right on the remaining half. The order of the left-right sequence was varied using sequences described by Fellows (1967). There were five such sequences which were varied over subjects. As mentioned before, the subjects were instructed either to look toward the sounding loudspeaker or the silent loudspeaker and then to return their eyes to the fixation point. A trial consisted of presenting the $300-\mathrm{msec}$ tone and awaiting the return of the eyes to the fixation target. There were 24 such trials. The intertrial interval was not fixed. It varied from 10 to $60 \mathrm{sec}$, so as to preclude anticipatory responses.

\section{RESULTS AND DISCUSSION}

The mean reaction time per subject was calculated in milliseconds and the data was normalized by a $\log _{10}$ conversion. The transformed data were then subjected to a completely randomized block factorial design, with three levels of frequency $(50,500$, and $5,000 \mathrm{~Hz})$, two levels of instruction (look toward the sounding loudspeaker or the silent loudspeaker), and two levels of rise time (.5 and $25.0 \mathrm{msec})$.

We expected that the ANOVA would reveal a main effect of instruction, that is, a tendency to react in the direction of the sounding loudspeaker significantly faster than toward the silent loudspeaker. We reasoned that perhaps the visual and auditory systems are linked together by a common physiological mechanism, so that the appearance of a tone would generate an orientation reflex of the eye. It logically followed that such a reflex would have to be triggered at the onset of the tone, perhaps by the time and intensity differences between the ears, which would also facilitate the localization of the tone. Thus the MSO, responding to interaural time differences, and a mechanism other than the MSO responding to intensity differences would be implicated in the orientation reflex.

On the basis of the above reasoning, we felt that the main effect of instruction should have held in all instances, except at $5,000 \mathrm{~Hz}$ at the $25.0-\mathrm{msec}$ rise time. The MSO should not be involved in localization or the initiation of an orientation response at $5,000 \mathrm{~Hz}$. These functions would be presumably be mediated by a mechanism other than the MSO, responding to interaural intensity differences. Interaural intensity differences available at the onset of a sound are reduced by increasing rise time. It would be expected, therefore, that the localizability of the $5,000-\mathrm{Hz}$ tone would be reduced, and that the orientation reflex would be attenuated, leading to a slowing down of the reaction time of eye movements toward the sound source. We expect- 
Table 1

Mean Reaction Times of Eye Movements Toward a Sounding Loudspeaker and Toward a Silent Loudspeaker Using 50-, 500 , or $5,000-\mathrm{Hz}$ Tones With Rise Times of .5 or $25.0 \mathrm{msec}$

\begin{tabular}{lrrrr}
\hline \multirow{2}{*}{ Loudspeaker } & $\begin{array}{c}\text { Rise Time } \\
(\mathrm{msec})\end{array}$ & 50 & 500 & 5,000 \\
\cline { 3 - 5 } & .5 & 281.2 & 269.1 & 274.9 \\
Sounding & 25.0 & 266.3 & 301.1 & 370.0 \\
& .5 & 346.4 & 376.3 & 400.1 \\
Silent & 25.0 & 330.6 & 380.5 & 370.4 \\
\hline
\end{tabular}

ed that this effect would have been disclosed by the ANOVA in terms of a significant three-way interaction between frequency, instruction, and rise time.

As expected, there was a main effect of instructions. While it took an average of $292.8 \mathrm{msec}$ to look toward the sounding loudspeaker, $367.4 \mathrm{msec}$ was required to look toward the silent loudspeaker. This difference was significant $[F(1,108)=38.7, p<.01]$. While the data supported all of the above speculations (refer to Table 1), the anticipated three-way interaction was not significant $[F(2,108)=1.87, p>.05]$. It was felt that this occurred because the effect, which was predicted for only 1 of 12 cells, was treated as random variation in the analysis, thereby adding to error. Thus, planned comparisons were performed, on the basis of the a priori logic outlined above.

Planned comparisons were used at each level of instruction and rise time to compare the reaction time at $5,000 \mathrm{~Hz}$ to 500 and $50 \mathrm{~Hz}$ combined. They were used to compare 500 to $50 \mathrm{~Hz}$ as well. The only effect disclosed was at the $25.0-\mathrm{msec}$ rise time, under the instruction to orient toward the sounding loudspeaker. The reaction time at $5,000 \mathrm{~Hz}$ was significantly slower than the other two frequencies combined $[\mathrm{F}(1,108)=12.1$, $\mathrm{p}<.01]$. The reaction times at 50 and $500 \mathrm{~Hz}$ did not differ.

In order to elaborate upon these findings, simple effects were used to compare the effect of instructions at each level of frequency and rise time. In addition, .5- and $25.0-\mathrm{msec}$ rise times were compared at each level of frequency and instruction. In summary, the subjects always reacted toward the sounding loudspeaker significantly faster than toward the silent loudspeaker, except at $5,000 \mathrm{~Hz}$ at the $25.0-\mathrm{msec}$ rise time. There was no significant effect of instruction in this instance. The simple effects also showed that there was no effect of rise time, except at $5,000 \mathrm{~Hz}$ under the instruction to orient toward the sounding loudspeaker. In this case, significantly more time was taken to respond at the $25.0-\mathrm{msec}$ rise time $[\mathrm{F}(1,108)=8.27, \mathrm{p}<.01]$.

Thus, our initial speculations were confirmed through the use of planned comparisons and simple effects. The obtained main effect of instruction cannot be explained in cognitive terms. That is to say, it cannot be argued that it is easier to orient toward a sound merely because we have learned to do so. This would not explain the failure to find a difference between instructions in the $25.0-\mathrm{msec}$ rise time, $5,000-\mathrm{Hz}$ condition. Rather, our data suggest that the ocular system reflexively orients toward sound and that this reflex action is mediated by one or more specialized mechanisms, such as the MSO.

\section{REFERENCES}

ERULKAR, S. D. Comparative aspects of spatial localization of sound. Physiological Reviews, 1972, 52, 237-360.

Fedderson, W. E., Sandel, T. T., Teas, D. C., \& Jeffress, L. A. Localization of high frequency tones. Journal of the Acoustical Society of America, 1957, 29, 988-991.

Fellows, B. J. Change in stimulus sequences for discrimination tasks. Psychological Bulletin, 1967, 67, 87-92.

Galambos, R., SchwartzkopfF, J., \& Rupert, A. Microelectrode study of superior olivary nuclei. American Journal of Physiology, 1959, 197, 527-536.

Goldberg, J. M., \& BRown, P. B. Functional organization of the dog superior olivary nucleus: An anatomical and electrophysiological study. Journal of Neurophysiology, 1968, 31, 639-656.

Guinan, J. J., Norris, B. E., \& Guinan, S. S. Single auditory units in the superior olivary complex. II: Locations of unit categories and tonotopic organization. International Journal of Neuroscience, 1972, 4, 147-166.

HALL, J. L. Binaural interaction in the acessory superior olivary nucleus of the cat. Journal of the Acoustical Society of America, $1965,37,814-823$.

Harrison, J. M., \& Feldman, M. L. Anatomical aspects of the cochlear nucleus and superior olivary complex. In W. D. Neff (Ed.), Contributions to sensory physiology (Vol. 4). New York: Academic Press, 1970.

IRVING, R., \& HARRISON, J. M. The superior olivary complex and audition: A comparative study. Journal of Comparative Neurology, 1967, 130, 77-86.

Masterton, B., JANE, J. A., \& Diamond, I. T. Role of brainstem auditory structures in sound localization. II: Trapezoid body, superior olive and lateral lemniscus. Journal of Neurophysiology, 1967, 30, 341-359.

Masterton, B., Thompson, G. C., Bechtold, J. K., \& RoBards, M. J. Neuroanatomical basis of binaural phasedifference analysis for sound localization: A comparative study. Journal of Comparative and Physiological Psychology, 1975, 89, 379-386.

Mills, A. W. Laterization of high-frequency tones. Journal of the Acoustical Society of America, 1960, 32, 132-134.

Rasmussen, G. L. Anatomical relationships of ascending and descending auditory systems. In W. Fields \& B. R. Alford (Eds.), Neurological aspects of auditory and vestibular disorders. Springfield, Ill: Charles C. Thomas, 1964.

Sandel, T. T., Teas, D. C., Feddersen, W. E., \& Jeffress, L. A. Localization of sound from single and paired sources. Journal of the Acoustical Society of A merica, 1955, 27, 842-852.

STOTLER, W. A. An experimental study of the cells and connections of the superior olivary complex of the cat. Journal of Comparative Neurology, 1953, 98, 401-431.

Strominger, N. L., \& Strominger, A. I. Ascending brainstem projection of the anteroventral cochlear nucleus in the rhesus monkey. Journal of Comparative Neurology, 1971, 143, 217-242.

(Received for publication October 11, 1977.) 